\title{
Identity-Based Organizations
}

\author{
Jean-Paul Carvalho* \\ Department of Economics 8 \\ Institute for Mathematical Behavioral Sciences \\ University of California, Irvine
}

\begin{abstract}
A single club model describes the collective production of both personal and social identity. Personal identity, how one perceives oneself, is formed through a process of cultural transmission. Social identity, how one is perceived by others, takes the form of collective reputation. Our model of identity-based organizations incorporates into the economics of identity insights from the economics of religion and cultural transmission. The identities that develop tend to be oppositional. Organizations devoted to more extreme identities are able to support higher levels of participation and collective action.
\end{abstract}

This version: 1 December 2015

JEL Classification: Z12, J22, D03

Keywords: Identity, club goods, economics of religion, cultural transmission

*Assistant Professor, Department of Economics \& Institute for Mathematical Behavioral Sciences, University of California, Irvine, 3151 Social Science Plaza, Irvine, CA 92697, jpcarv@uci.edu

This paper has benefitted from comments by George Akerlof, Robbie Akerlof, Rachel Kranton, Mario Ferrero, Mike McBride, Peyton Young and seminar/conference participants at Nuffield College, Oxford; University of Leicester; the Summer Colloquium on Identity Economics, London; the IMBS, UC Irvine; 2015 ASREC annual conference; Workshop on The Economics of Cultural Transmission and Evolution, Paris. All errors are mine. 


\section{Introduction}

A person's identity is the way she is perceived by herself (personal identity) and by others (social identity). For example, "I am a believer in doctrine $x$ ", "I am racially/morally superior", "I am hailed as a martyr." Forms of identity such as these can be valued per se. In their seminal work on the subject, Akerlof \& Kranton (2000, 2010) develop a framework for analyzing the role of identity in economics. Inter alia, one's ascriptive characteristics determine one's choice of identity. One's identity in turn imposes specific norms which shape one's actions. We build on the Akerlof-Kranton framework by treating identity as a cultural trait which is cultivated in groups. ${ }^{1}$ In doing so, we bring together three literatures - the economics of identity, cultural transmission and religion - which have been largely separate.

Identity formation is an inescapably social process. Suppose, for example, that an individual invests time/effort in acquiring a system of metaphysical and moral beliefs. These beliefs, if acquired, can be undermined by contact with nonbelievers (Iannaccone \& Berman 2006, p. 116). Likewise, beliefs can be reinforced by contact with believers, with little personal investment. In this sense, identity is a cultural trait that is produced and socially transmitted, as in seminal work by Bisin \& Verdier (2000) and Bisin et al. (2011). The insight developed in this paper is that the cultural transmission process produces its own externality and free-rider problems. It is natural that organizations emerge to solve and possibly exploit these problems.

Cultural transmission in groups is studied by several recent papers (Carvalho \& Koyama 2015, Carvalho et al. 2015). In this paper, identity-based organizations provide an environment in which identities are formed and socially reinforced. ${ }^{2}$ They cultivate identity by performing two functions: (1) imposing rules of participation in identity-producing activities and (2) excluding nonmembers from social interactions.

\footnotetext{
${ }^{1}$ That identity is a product of strategic interaction is entirely consistent with Akerlof \& Kranton (2000, p. 723-724).

${ }^{2}$ Benabou \& Tirole (2011) present a self-signaling model of identity in which individuals can make personal investments that reinforce their identity.
} 
Participation can produce identity in many ways. Communal prayer, scriptural study and religious sacrifice converts one into a believer in a religious organization's doctrine. Donating to one's alma mater confers identification with the institution and a share in its prestige. Participation in a white supremacist organization cultivates a sense of racial superiority. Joining a violent rebelion gains one recognition as a martyr.

By excluding nonmembers, who have not participated in the same identity-producing activities, an organization confines members' exposure to like-minded individuals. This cultivates personal identity by regulating social transmission. It also produces social identity through group reputation for possessing an (unobservable) trait, akin to statistical discrimination (Coate \& Loury 1993).

Because identity-formation is based on the exclusion of nonmembers, identity can be viewed as a club good, a central subject of the economics of religion (Iannaccone 1992, Berman 2000, Aimone et al. 2013). In this paper, we formalize the notion that identity formation, both personal and social, has a similar structure to the production of (rival) club goods. The analysis yields new predictions by linking an organization's doctrine to its ability to induce sacrifices by members and coordinate collective action. Carvalho (in progress) studies a dynamic extension of this model, showing how identity formation leads to various forms of cultural cycles.

\section{The Basic Model}

Society consists of a finite set of risk-neutral individuals $I$. The population $I$ is partitioned into two (nonempty) communities $I_{0}$ and $I_{1}$ (e.g. secular and religious).

Individuals end the game with one of two identities $k \in\{0,1\}$. We refer to identity 0 as the mainstream identity and identity 1 as the alternative identity, for reasons to be apparent shortly. Community membership determines identity preferences. Each $i \in I_{k}$ strictly prefers identity $k$ to the other identity. Hence we at times refer to members of $I_{0}$ as mainstream 
types and members of $I_{1}$ as alternative types.

While an individual is born into a community, her participation in an identity-based organization is chosen. There are two organizations, also indexed by $k \in\{0,1\}$. Organization $k$ cultivates identity $k$ and thereby caters to community $I_{k}$.

An individual's type is two-dimensional. Firstly, $\theta$ denotes an individual's ideal identity. That is, if $i \in I_{k}$, then $i$ 's type is $\theta=k$. Let $\pi_{\theta k}$ be the payoff to a type $\theta$ agent from acquiring identity $k$. By definition, $\pi_{00}>\pi_{01}$ and $\pi_{11}>\pi_{10}$. Secondly, each individual bears a privately known fixed cost $c$ of joining an organization. We can think of $c$ as an individual's degree of individualism or aversion to group participation. The membership cost $c$ is determined by an independent draw from the distribution $F$. For a given agent, $c$ is the same across organizations. The distribution $F$ is the same across individuals (i.e. independent of $\theta$ ). We assume $F(0)=0$ and $F$ is twice differentiable and strictly log-concave on $(0, \infty)$.

The timing of the game is as follows. Each organization $k$ announces its strictness $s_{k}$, which is the minimum level of participation demanded of its members. Alternatively, strictness could be interpreted à la Iannaccone (1992) as the level of 'sacrifice' required of members. Religious organizations for example may prohibit certain dietary and sexual practices. Once announced, an organization remains committed to $s_{k}$.

Observing $\left(s_{0}, s_{1}\right)$, each individual $i$ chooses to become a member of an organization, $m_{i}=k$, or be unaffiliated, $m_{i}=n . M_{k}$ is the set of organization $k$ members. The set of unaffiliated individuals is $N=I-M_{0}-M_{1}$.

Each member $i \in M_{k}$ chooses a level of participation $x_{i}$ in group $k$ 's activities, at quadratic cost $x_{i}^{2}$. We assume simply that members of group $k$ are constrained to choose $x_{i} \geq s_{k}$. Unaffiliated agents cannot participate, i.e. $x_{i}=0$ for all $i \in N$.

From this point, we can specify two variants of the model to capture personal and social identity. These variants end up having the same mathematical structure. 
A. Social Transmission 8 Personal Identity. An individual concerned with personal identity wishes to acquire and retain a particular identity. Assume that with probability $x_{i}$, i.e. her degree of participation, $i \in M_{k}$ becomes a 'carrier' of identity $k{ }^{3}$ With probability $1-x_{i}$, $i$ becomes a carrier of the mainstream identity 0 . Hence the mainstream identity is the 'default' identity. We think of it as the identity supported by prevailing norms, the media, the education system and/or the state. This implicitly relies upon a centralized socializing agent, unlike standard work, but as in Carvalho \& Koyama (2015).

If $i \in M_{k}$, she is exposed to all other members of group $k$ (including herself). One individual $j \in M_{k}$ is chosen uniformly at random to be her 'role model'. If $j$ is a carrier of identity $\kappa \in\{0,1\}, i$ ends the period with identity $\kappa$. Hence the likelihood that $i \in M_{k}$ acquires identity $k$ through a role model equals the group's average participation level:

$$
\bar{x}_{k} \equiv \frac{1}{\left|M_{k}\right|} \sum_{j \in M_{k}} x_{j} .
$$

Likewise for unaffiliated agents, a role model is chosen uniformly at random from $N$. Since $x_{i}=0$ for all $i \in N$, each unaffiliated agent acquires the mainstream identity with probability one.

B. Collective Reputation \& Social Identity. An individual concerned with social identity wants to communicate her identity to others. Suppose that $i \in M_{k}$ acquires identity $k$ with probability $x_{i}$, and the mainstream identity with complementary probability. We assume that an individual's identity and participation level are private information, but her group membership is publicly observable. In addition, the average participation of group members is public, as in the statistical discrimination literature (e.g. Coate \& Loury 1993). Hence from the perspective of $j \neq i$, the likelihood that $i \in M_{k}$ has identity $k$ is $\bar{x}_{k}$.

Thus personal and social identity formation have the same structure. Regardless of which form of identity we have in mind, the expected payoff to a $(\theta, c)$-type agent $i$ who joins $k$ is

$$
u_{i}(\sigma, s)=\pi_{\theta k} \bar{x}_{k}+\pi_{\theta 0}\left(1-\bar{x}_{k}\right)-x_{i}^{2}-c .
$$

\footnotetext{
${ }^{3}$ Later, we shall introduce a restriction that keeps $x_{i} \in[0,1]$ for all $i \in I$.
} 
As the probability that $i \in N$ acquires identity $k=1$ is zero, the payoff when unaffiliated is $\pi_{\theta 0}$.

Since an individual's payoff is determined by the average participation of fellow group members, identity is analogous to a rival club good, produced by a voluntary contribution mechanism with contribution cost $x_{i}^{2}-c$ and return $\pi_{\theta 0}+\bar{x}_{k}\left(\pi_{\theta k}-\pi_{\theta 0}\right)$ (see Aimone et al. 2013). Thus, our model applies to agents who care both about identity and material club goods. This unifies several literatures and yields new predictions, as we shall see.

Rather than maximizing members' welfare, we assume that each organization $k$ sets strictness $s$ to maximize total participation in its activities, defined as:

$$
X_{k}=\sum_{j \in M_{k}} x_{j} .
$$

Hence individuals may join an organization to cultivate a particular identity, but the organization itself may have other objectives, such as social service provision, political opposition and violent rebelion.

The structure of the game is common knowledge and we restrict attention to pure strategies.

\subsection{Mainstream versus Alternative Identities}

Let us define tension here as the benefit to type-1 agents from acquiring the alternative identity, $\tau \equiv \pi_{11}-\pi_{10}$. To ensure interior solutions, we assume $\tau \leq 1$. When $\tau$ is close to one, alternative types get a much larger payoff from the alternative identity, viz. the mainstream identity is a poor substitute for the alternative one. In such cases, the alternative organization is said to be at high tension with mainstream society. We can now state the following result. Proofs are in the appendix.

Proposition 1 There exists a unique subgame perfect equilibrium [SPE] of this game. In this equilibrium: 
(i) All type-0 individuals remain unaffiliated: $I_{0} \subset N$.

(ii) Organization 0 attracts no members: $M_{0}=\emptyset$.

(iii) For all $i \in M_{1}$, the participation rule binds: $x_{i}^{*}=s_{1}^{*}$.

(iv) For organization 1, strictness is $s_{1}^{*} \in\left(\frac{1}{2} \tau, \tau\right)$ and expected membership size is $\left|M_{1}^{*}\right| \in$ $\left(0,\left|I_{1}\right|\right)$.

Identity formation is an inescapably social process. This is captured here in a deliberately stark manner. Individual participation only makes one a carrier of an identity; it has little effect on one's ultimate or expected identity. That is the product of social transmission and inference, which in turn depend on participation levels across the entire group. Hence there is a severe free-rider problem in identity formation. The best an individual can do is to save entirely on the cost of collective participation and free ride on the identity-forming efforts of other group members. Because all individuals face this incentive, no participation occurs without rules imposed by the organization, and nobody participates more than required [Proposition 1(iii)].

What kind of identity-based organization can attract members? Organizations that cultivate a mainstream identity are never joined [Proposition 1(ii)], since individuals can acquire a mainstream identity without incurring the costs of group membership. Hence all individuals who desire a mainstream identity remain unaffiliated [Proposition 1(i)].

In contrast, organizations that cultivate an alternative identity can attract members, as long as they impose an intermediate level of strictness $s_{1} \in(0, \tau)$. A totally lax organization $\left(s_{1}=0\right)$, does nothing to mitigate the free-rider problem in identity formation and cannot compensate for the cost of membership, however low it may be. On the other hand, if strictness is too high $\left(s_{1} \geq \tau\right)$, the organization is successful at identity formation, but at a prohibitively high cost. ${ }^{4}$ In the intermediate range, the alternative organization faces a tradeoff between participation intensity and membership size. By raising its strictness

\footnotetext{
${ }^{4}$ Berman (2000) and McBride (2015) show how very strict groups can survive through high fertility rates.
} 
$s_{1}^{*}$ beyond the individual welfare-maximizing level $\tau / 2$, it increases participation among members, but only attracts individuals who have a low cost of joining. Implicit solutions for the equilibrium strictness level $s_{1}^{*}$ and membership $M_{1}^{*}$ are derived in the proof of Proposition $1($ iv).

\subsection{Tension, Participation \& Collective Action}

Tension is an important concept in the sociology of religion. Stark \& Finke (2000) propose that "[a]ll religious groups can be located along an axis of tension between the group and its sociocultural environment", where tension is defined in terms of "distinctiveness, separation, and antagonism" [p. 143].

It turns out that our identity-based notion of tension dictates how strict an organization can be and how much total participation it can generate:

Proposition 2 In the SPE, organization 1's strictness $s_{1}^{*}$ and total participation $X_{1}^{*}$ are strictly increasing in tension $\tau$.

When tension is high, it is more costly for alternative individuals to remain unaffiliated and acquire a mainstream identity. This relaxes the tradeoff between participation intensity and membership size. Therefore, high-tension organizations are able to impose more onerous demands on members and induce higher levels of total participation. This is the analog of results produced by Bisin \& Verdier (2000) and Bisin et al. (2011), outside of an organizational context, on the persistence of minority cultures and oppositional identities. Inter alia, our result explains why oppositional identities tend to form the basis for collective action, as elaborated below.

When there is free entry by organizations, or organizations maximize members' welfare or size of membership, one can show that $s_{1}^{*}=\tau / 2$. Once again, higher tension increases equilibrium strictness and total participation. 


\section{Religious Doctrine \& Strictness}

The economics of religion has focussed largely on religious practice. Organizations that are stricter in terms of their practical requirements (dietary, sexual, sartorial etc.) are more successful at recruitment and retention (Iannaccone 1992). No link between doctrine and strictness has been analyzed. One question that arises is why don't all religious organizations raise their strictness? Why aren't Episcopalian congregations as demanding of members as Jehovah's Witnesses? ${ }^{5}$

A sociological conception of religion is one of "a unified system of beliefs and practices" (Durkheim 1915). Our model shows how an organization's belief system might dictate its strictness. Non-affiliation is more costly for an individual who wishes to acquire, or be seen to acquire, religious beliefs that are "further" from the mainstream belief system (e.g. creationism). Hence religious organizations that cultivate more extreme belief systems can be more extreme in terms of their practical demands of members. Episcopalian congregations are unable to raise strictness, because beliefs prevailing in mainstream society are a close substitute for their belief system.

\section{Oppositional Identity \& Collective Action}

Social movements involve well known free-rider problems, apart from the problems of identity formation. Their goals are often distant and improbable (e.g. terrorist organizations). Individually, participants make little difference, but bear the full cost of contributing. More immediate rewards may be required to motivate participants. In our model, collective action is a byproduct of individuals' identity-forming activities. Identity-based organizations are successful at achieving tangible goals, because participation in their activities cultivates desired forms of identity. Social movements, such as the suffrage, temperance, civil rights and

\footnotetext{
${ }^{5}$ For example, $46.1 \%$ of Evangelical Protestants attend religious services at least weekly, compared to $22.8 \%$ of mainline protestants (Baylor University 2007). See McBride (2015) for consistent evidence on financial contributions across religious groups.
} 
gay rights movements, all promoted identities among activists that were opposed to mainstream forms of identification. Thus solving the free-rider problem in identity formation solves the free-rider problem in more tangible forms of collective action, in our model.

Religious organizations are exceptionally effective at collective action, including public good provision, political opposition and violent rebelion (e.g. Gruber \& Hungerman 2007, Berman 2009). For example, the Muslim Brotherhood in Egypt operated a vast network of social services, including schools, mosques and healthcare clinics. Berman (2009) shows how the success of religious groups in terrorism is linked to their strict club structure. In addition, we suggest that this strict club structure is supported by belief systems that are divorced from mainstream thought (e.g. apocalyptic beliefs). Indeed, religious organizations expend an extraordinary amount of resources cultivating metaphysical and moral beliefs, as well as ingroup identification. Thus, in light of our theory, it is unsurprising that they are so effective at collective action.

\section{References}

Aimone, J. A., Iannaccone, L. R., Makowsky, M. D. \& Rubin, J. (2013), 'Endogenous group formation via unproductive costs', Review of Economic Studies 80(4), 1215-1236.

Akerlof, G. A. \& Kranton, R. E. (2000), 'Economics and identity', Quarterly Journal of Economics 415(3), 715-753.

Akerlof, G. A. \& Kranton, R. E. (2010), Identity Economics: How our Identities Shape our Work, Wages and Wellbeing, Princeton University Press, Princeton, NJ.

Baylor University (2007), The Baylor Religion Survey Wave II, Baylor Institute for Studies of Religion, TX.

Benabou, R. \& Tirole, J. (2011), 'Identity, morals, taboos: Beliefs as assets', Quarterly Journal of Economics 126, 805-855. 
Berman, E. (2000), 'Sect, subsidy, and sacrifice: an economist's view of ultra-orthodox Jews', Quarterly Journal of Economics 115(3), 905-953.

Berman, E. (2009), Radical, Religious, and Violent: The New Economics of Terrorism, MIT Press, Cambridge, MA.

Bisin, A., Patacchini, E., Verdier, T. \& Zenou, Y. (2011), 'Formation and persistence of oppositional identities', European Economic Review 55, 1046-1071.

Bisin, A. \& Verdier, T. (2000), 'Beyond the melting pot: cultural transmission, marriage, and the evolution of ethnic and religious traits', Quarterly Journal of Economics 115(3), 955988.

Carvalho, J.-P. (in progress), 'Cultural contests and cycles', work in progress.

Carvalho, J.-P. \& Koyama, M. L. (2015), 'Resisting education', working paper, University of California, Irvine.

Carvalho, J.-P., Koyama, M. L. \& Sacks, M. (2015), 'Community fragmentation and fragility', work in progress.

Coate, S. \& Loury, G. (1993), 'Will affirmative-action policies eliminate negative stereotypes?', American Economic Review 83, 1220-1240.

Durkheim, E. (1915), The Elementary Forms of the Religious Life, G. Allen \& Unwin, London, UK.

Gruber, J. \& Hungerman, D. M. (2007), 'Faith-based charity and crowd-out during the great depression', Journal of Public Economics 91(5-6), 1043-1069.

Iannaccone, L. R. (1992), 'Sacrifice and stigma: Reducing free-riding in cults, communes, and other collectives', Journal of Political Economy 100(2), 271-291.

Iannaccone, L. R. \& Berman, E. (2006), 'Religious extremism: The good, the bad, and the deadly', Public Choice 128, 109-129. 
McBride, M. (2015), 'Why churches need free-riders: religious capital formation and religious group survival', Journal of Behavioral and Experimental Economics 58, 77-87.

Stark, R. \& Finke, R. (2000), Acts of Faith: Explaining the Human Side of Religion, University of California Press, Berkeley, CA. 


\section{Appendix (For web publication)}

Proof of Proposition 1. Firstly, a type $\theta$ agent $i$ will join $k=0$ if and only if:

$$
\pi_{\theta 0}-x_{i}^{2}-c>\pi_{\theta 0}
$$

which clearly does not hold for any $\theta$ and pair $x_{i} \geq 0$ and $c>0$. Therefore, $M_{0}=\emptyset$. This establishes part (ii).

A type $\theta$ agent $i$ will join $k=1$ if and only if:

$$
\pi_{\theta 1} \bar{x}_{1}+\pi_{\theta 0}\left(1-\bar{x}_{1}\right)-x_{i}^{2}-c>\pi_{\theta 0}
$$

Clearly, this cannot hold for $\theta=0$, since $\pi_{00}>\pi_{01}$. Hence all $i \in I_{0}$ remain unaffiliated, establishing part (i).

To establish part (iv), suppose for the moment that $x_{i}=s_{1}$ in equilibrium. Substituting this into (1), inequality (4) holds for $i \in I_{1}$ if and only if:

$$
c<\left(\pi_{11}-\pi_{10}\right) s_{1}-s_{1}^{2}=\tau s_{1}-s_{1}^{2} \equiv \bar{c}
$$

Therefore, $\left|M_{1}\right|=\left|I_{1}\right| F(\bar{c})$. By the assumptions on $F,\left|M_{1}\right| \in(0,1)$ if and only if $0<$ $s_{1}<\tau$. Hence one can restrict attention to $s_{1} \in(0, \tau)$, because the organization's objective function $X_{1}$ equals zero otherwise.

Thus, the organization's problem is:

$$
\max _{s_{1}}\left|I_{1}\right| F\left(\bar{c}\left(s_{1}\right)\right) s_{1}
$$

subject to $0<s_{1}<\tau$. The first-order condition for an interior optimum is:

$$
\frac{F\left(\bar{c}\left(s_{1}\right)\right)}{F^{\prime}\left(\bar{c}\left(s_{1}\right)\right)}=\left(2 s_{1}-\tau\right) s_{1} .
$$

Consider the LHS of (7). Recall that $F$ is twice differentiable and strictly log-concave, so the LHS is continuous and strictly increasing in $\bar{c}$. From $(5)$, on $\left[0, \frac{1}{2} \tau\right), \bar{c}\left(s_{1}\right)$ is continuous and 


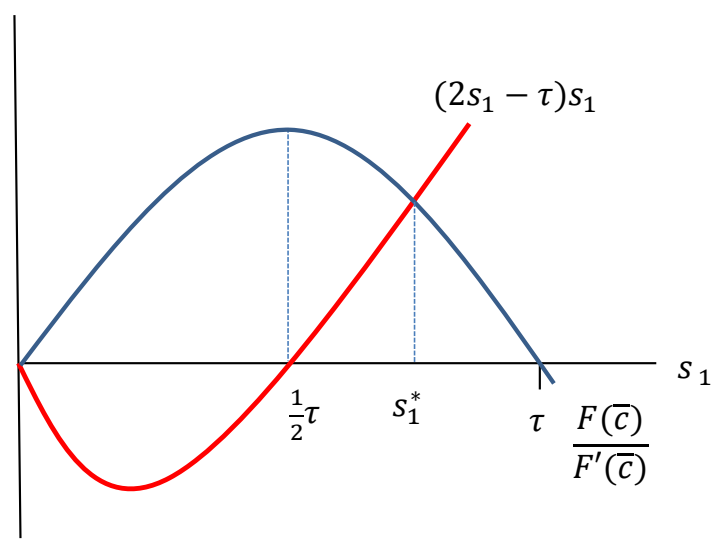

(a) Equilibrium

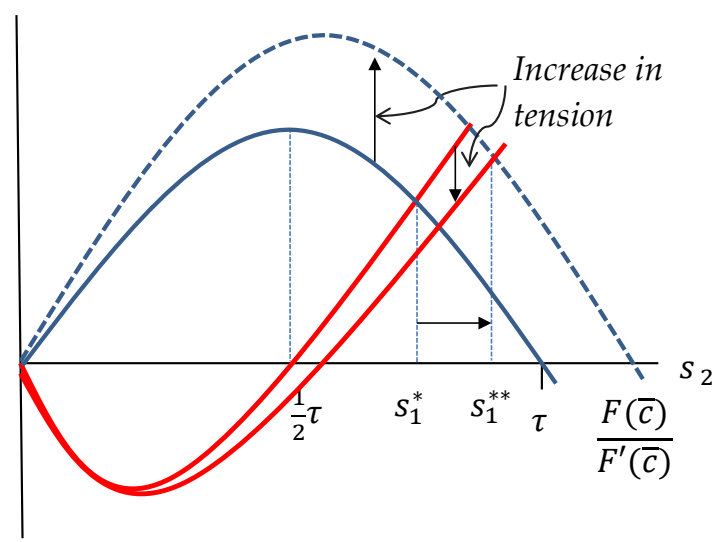

(b) Comparative Static

Figure 1: Equilibrium strictness $s_{1}^{*}$ is strictly decreasing in tension $\tau$.

strictly increasing in $s_{1}$. On $\left(\frac{1}{2} \tau, \tau\right), \bar{c}\left(s_{1}\right)$ is continuous and strictly decreasing. Therefore, the LHS is continuous, strictly increasing in $s_{1}$ on $\left[0, \frac{1}{2} \tau\right)$ and strictly decreasing in $s_{2}$ on $\left(\frac{1}{2} \tau, \tau\right)$.

In addition, since $F(0)=0$ and $F^{\prime}(0)>0$, the LHS equals zero for $s_{1} \in\{0, \tau\}$ and is positive for $s_{1} \in(0, \tau)$.

The RHS of (7) is nonpositive for $0 \leq s_{1} \leq \frac{1}{2} \tau$ and positive and strictly increasing in $s_{1}$ for $s_{1}>\frac{1}{2} \tau$.

Therefore, the two curves intersect at some unique value $s_{1}^{*} \in\left(\frac{1}{2} \tau, \tau\right)$. The solution is depicted in figure 1(a). Clearly, the second-order condition for a maximum holds at $s_{1}^{*}$.

Finally, let us establish part (iii). Suppose that $x_{i}>s_{1}$ in equilibrium. Differentiating (1) with respect to $x_{i}$ yields the first-order condition

$$
\frac{\pi_{\theta 1}-\pi_{\theta 0}}{\left|M_{1}\right|}-2 x_{i}=0
$$

and the unconstrained optimizer

$$
x_{i}=\frac{\tau}{2\left|M_{1}\right|},
$$

for all $i \in M_{1}$. We have already established that the optimal symmetric participation profile 
from organization 1's perspective involves $x_{i}=s_{1}^{*}>\tau / 2$, which is greater than or equal to (8). Hence $x_{i}^{*}=s_{1}^{*}$ for all $i \in M_{1}$.

Proof of Proposition 2. An increase in $\tau$ causes the LHS of (7) to shift up and the RHS to shift down. This implies that $s_{1}^{*}$ is strictly increasing in $\tau$, as depicted in figure 1(b).

Finally, consider total participation, $X_{1}^{*}\left(s_{1}^{*}\right)$. By the envelope theorem:

$$
\begin{aligned}
\frac{d X_{1}^{*}\left(s_{1}^{*}\right)}{d \tau} & =\frac{\partial X_{1}^{*}\left(s_{1}^{*}\right)}{\partial \tau} \\
& =F^{\prime}\left(\bar{c}\left(s_{1}^{*}\right)\right) \frac{\partial \bar{c}\left(s_{1}^{*}\right)}{\partial \tau} \\
& =F^{\prime}\left(\bar{c}\left(s_{1}^{*}\right)\right) s_{1}^{*}>0 .
\end{aligned}
$$

